\title{
EDITORIAL
}

\section{Solar Energy for sustainable development in developing countries}

Sustainable development is the important gift that we can leave for our future generations. It is of vital importance to develop different types of renewable energy sources including solar, wind, hydro, biomass, geothermal and hydrogen gas to supply the energy needed for sustainable development in a country. Among these, Solar Energy has been identified as one of the promising renewable energy sources which has the potential to meet the future energy demand in developing countries like Sri Lanka.. To achieve this, solar energy can be harnessed either by generating electricity using solar panels (solar photovoltaic or PV) or directly by using solar thermal effect to generate heat.

Government and private sector organizations can largely contribute to sustainable development efforts in a country by increasing and facilitating its solar PV research and installations. Funding for PV installation projects can be sought through direct government investments, through bank loans and subsidy schemes, private sector investments and donations by non-governmental organizations. A large part of the cost of a solar $\mathrm{PV}$ installation is for the initial investment and as more and more such schemes are implemented and people volunteer their professional and technical services at community level, the solar energy can become cheaper. The investment will pay for itself for the rest of the life time of the PV installation, which is typically around 20-25 years. When more and more new solar PV systems are installed in a country, the solar electricity is expected to become more affordable to the ordinary consumer. Ken Zweibel of George Washington University predicts that Silicon solar panels can last may be up to a 100 years as there is only a small degradation of performance - about $1 / 2 \%$ per year. A solar panel after 50 years will therefore produce electricity at $75 \%$ of its original performance.

Harnessing the solar energy is well within our scientific and technological capabilities and for developing countries, this provides a golden opportunity. Solar energy is also an environmentally friendly energy source and it will gradually replace the traditional but environmentally harmful methods of energy generation using fossil fuel burning for electrical power generation.

Due to the extensive research being conducted in developing cost efficient solar cells, solar panels are becoming cheaper and more and more popular among the consumers. The higher competition among manufacturers also contributes to cheaper solar panels, down to less than 1.0 and 0.5 dollar per watt for Silicon and Thin film solar panels, respectively. Applications of solar power in a country can be from individual houses to large solar farms with few hundred solar PV units and from electrical vehicles to national grids, reflecting the diverse needs of a developing country.

Solar energy received by the earth (100 000 TW) is more than 66,000 times greater than the annual worldwide electricity consumption (1.5 TW). A simple calculation shows that $10 \%$ efficient solar panels covering $0.3 \%$ of the total land area of Sahara desert is sufficient to supply the electricity needed for the entire world! It is advantages that many developing countries are situated near the equator where there is an ample amount of sunshine almost year-round. Therefore, it has become a natural choice to harness solar energy by setting up solar photovoltaic (PV) systems in these countries. 
For many countries, the development of solar photovoltaic systems for power generation is expected to (a) save money, especially foreign exchange spent on imported fossil fuels, (b) create more jobs per unit of electricity produced compared to petroleum, coal and nuclear power plants, (c) reduce considerably the oil and coal imports, (d) protect the environment by reducing pollution and (e) increase the energy independence and energy security.

Governments in many developing countries offer substantial incentives to strengthen the solar PV installations due to long term environmental and economic advantages. These include lower carbon dioxide emissions and the creation of high technology jobs within the solar PV industry. In order to develop and sustain the solar PV as a major renewable energy source, the country should have a well-trained workforce who would be competent in handling solar PV related technological issues ranging from manufacturing, installation and repair and maintenance.

P. Ravirajan 